\title{
DEVELOPMENT OF AN IMPROVED EARTHING METHOD FOR POWER AND DISTRIBUTION TRANSFORMERS SUBSTATIONS
}

\author{
L. M. Adesina ${ }^{1,{ }^{*}}$ and T. 0. Akinbulire ${ }^{2}$ \\ 1, ENGINEERING \& STANDARDIZATION, EKo ELECTRICITY DisTRIBUTION Co., LAGOS, LAGOS STATE, NIGERIA. \\ 2, DEPT. OF ELECTRICAL \& ELECTRONIC ENGINEERING, UNIVERSITY OF LAGOS, AKOKA, LAGOS STATE, NIGERIA \\ E-mail addresses: ${ }^{1}$ lambe.adesina@ekedp.com, ${ }^{2}$ Imamaj@yahoo.com
}

\begin{abstract}
Engineers and planners have realized that equipment grounding is a necessary part of installation process in Electrical power substations. Over years, grounding or earthing has been carried out primarily through preparation of Earth Mat which is interconnected with several Earth-rods buried around the equipment under consideration. This approach takes several efforts to have an acceptable and reliable result. However, this paper presents a more flexible, economical and results oriented approach. A flow chart which describes the procedures of carrying out the proposed method of earthing is developed. This was applied to two case studies: a proposed Power transformer substation and distribution Transformer substation located within the same geographical domain. On the two cases, the measured earth resistances are presented and discussed. The results from the case study indicates that the earth resistance values obtained from this new approach are reliable and in compliance with IEEE Standards 80,142, 81 and 1100.
\end{abstract}

Keywords: Equipment, Grounding, Earthing, Earth-rod, Flowchart, Earth Mat, Flow Process, Injection Substation, Distribution Substation, Earth Resistance, IEEE Standard.

\section{INTRODUCTION}

Power System installations and equipment need grounding systems [1-5]. Generally, grounding systems consist of grids integrated with rods at each corner. In modern extra-high-voltage and ultra- high voltage AC substations, grounding has become one of the dominant problems of system design. It is essential to have an accurate design procedure for the grounding system. Grounding provides an increase in the reliability of the electricity supply service as it enhances stability of voltage conditions, preventing excessive voltage peaks during disturbances, and a means of providing a measure of protection against lightning [1-3]. It is required that the voltage rise during a fault be kept to low levels. This dictates that ground resistances in high voltage substations must be very low. The most common method of obtaining low values of ground resistance at high-voltage substations is to use interconnected ground grids.

Over time, corrosive soils with high moisture content, high salt content, and high temperatures can degrade ground rods and their connections. Although the ground system when initially installed, had low earth ground resistance values, the resistance of the grounding system can increase if the ground rods are eaten away [2, 3]. Grounding testers, are indispensable troubleshooting tools to help one maintain uptime. With frustrating, intermittent electrical problems, the problem could be related to poor grounding or poor power quality. That is why it is highly recommended that all grounds and ground connections are checked at least annually as apart of normal Predictive Maintenance plan. During these periodic checks, if an increase in resistance of more than $20 \%$ is measured [1], it is required to investigate the source of the problem and make the correction to lower the resistance, by replacing or adding ground rods to the ground system.

Therefore, to bring the incessant Earth failure to the barest minimum, Engineers designed earthing system for both Distribution substation and injection substation. However, there is need to know the regulations and the expected Earth resistance values in different utility companies that requires the supply of electricity. The lower the ground resistance, the safer for people and better protection for the equipment. The IEEE Standard 80 [6] and IEEE Standard 142 [7] state that the earth resistance for large HV substation should 
be less than 1.0 Ohm especially for Power Transformers of ratings 7.5 MVA, 33/11 KV and above. But for cases of Distribution Transformer either $33 / 0.415 \mathrm{kV}$ or $11 / 0.415 \mathrm{kV}$ having capacity ranging from $100 \mathrm{KVA}$ to $2 \mathrm{MVA}$ [7], it is often difficult to achieve this earth resistance values.

It worth noting that the old conventional ways of doing Power Transformer substation earthing was to dig a large pit and bury all the earth rods and just brought out about two leads which will be extended to all the power transformers and substation equipment.

Factors influencing resistance of grounding (Earthing) electrode systems include, [7-9]

- The resistance of the electrode is a function of the material of the rod and the surface area of the rod. The surface area of the rod is a function of the rod diameter.

- Difference in ground rod sizes and materials make little appreciable difference in the resistance of the electrode.

The contact resistance between the rod and the surrounding soil also varies depending on the compatibility of the soil. For example, if the rod is driven into well compacted soil, then the resistance between the rod and the surrounding soil is not a significant factor.

Thus, in a properly installed grounding electrode system, soil resistance is the key factor that determines what the resistance of a grounding electrode will be and to what depth a rod must be driven to obtain low ground resistance. This imply that the resistivity of soils varies with the depth from the surface and the electrolyte in the soil (the type of concentration of soluble chemical in the soil, the moisture content and soil temperature).

\section{IMPORTANCE OF EQUIPMENT GROUNDING IN POWER SYSTEM}

Equipment grounding in power system is of significant importance to the life of Equipment as well as human operating them. Some of them are discussed as follows [10-12].

\subsection{Safety of Human life / Building / Equipment}

- Save human life from danger of electrical shock or death by blowing a fuse i.e. to provide an alternative path for the fault current to flow so that it will not endanger the user

- Protect buildings, machinery and appliances under fault conditions

- Ensure that all exposed conductive parts do not reach a dangerous potential
- Prevent or at least minimize damage to equipment because of heavy fault current (short circuit current) and Lightning and thus improve the reliability of Equipment.

- Provides stable platform for operation of sensitive electronic equipment i.e. maintaining the voltage at any part of an electrical system at a known value to prevent overcurrent or excessive voltage on the appliance or equipment.

\subsection{Overvoltage Protection}

Lightning, Line surges or Unintentional Contact with higher voltage lines can cause dangerously high voltages to the electrical distribution system. Earthing provide an alternative path around the electrical system to minimize damages in the system.

\subsection{Voltage Stabilization}

In power system network, there are various sources of system electricity supply. For example, every Transformer in the system can be considered a separate source. If there were not a common reference point for all these voltage sources, it would be extremely difficult to establish relationships with each other.

\subsection{Protection of system}

The reliability of the power supply is generally improved.

\section{PARALLEL CONNECTION OF EARTH PIT RESISTANCES IN SYSTEM GROUNDING.}

A Parallel circuit is one with several different paths for the electricity to travel $[8,9]$. It is like a river that has been divided up into smaller streams, however, all the streams come back to the same point to form the river once again.

Resistors in parallel, on the other hand, result in an equivalent resistance that is always lower than every individual resistor $[9,13]$. If voltage is applied across a resistor, certain amount of current flows. If another resistor is added in parallel with the first one, one would have essentially opened a new channel through which more current can flow. No matter how large the second resistor is, the total current flowing from the power supply will be at least slightly higher than the current through the single resistor. And if the total current is higher, the overall resistance must be lower. Consider a 15 MVA 33/11 kV power Injection Substation where the resistance of six number earth pit are $R_{1}, R_{2}, R_{3}, R_{4}, R_{5}$ and $R_{6}$ and are connected in 
parallel. The resultant resistance $\mathrm{R}_{\mathrm{T} 1}$, is shown in equation (1) [2,14];

$$
R_{T 1}=\frac{R_{1} R_{2} R_{3} R_{4} R_{5} R_{6}}{A+B+C+D+E+F}
$$

Where,

$A=R_{2} R_{3} R_{4} R_{5} R_{6} ; \quad B=R_{1} R_{3} R_{4} R_{5} R_{6}$

$C=R_{1} R_{2} R_{4} R_{5} R_{6} ; \quad D=R_{1} R_{2} R_{3} R_{5} R_{6}$

$E=R_{1} R_{2} R_{3} R_{4} R_{6} ; \quad F=R_{1} R_{2} R_{3} R_{4} R_{5}$

In the same way, for a $500 \mathrm{KVA}, 33 / 0.415 \mathrm{KV}$

Distribution Transformer Substation, the equivalent resistance $\left(\mathrm{R}_{\mathrm{T} 2}\right)$ of 4 № Earth pit required is also shown in equation (2) $[2,14]$;

$$
R_{T 2}=\frac{R_{1} R_{2} R_{3} R_{4}}{(A+B+C+D)}
$$

Where,

$A=R_{2} R_{3} R_{4} ; B=R_{1} R_{3} R_{4} ; C=R_{1} R_{2} R_{4} ; D=R_{1} R_{2} R_{3}$

\section{PROPOSED WORK SPECIFICATION FOR STANDARD GROUNDING OF POWER SYSTEM SUBSTATION AND DEVELOPMENT OF FLOWCHARTS}

The general procedures of carrying out Grounding or Earthing in typical Injection and Distribution Transformer Substations are as shown below including the flowchart shown in figure 1. This flowchart illustrates the flow process in obtaining a very good grounding results.

4.1 Procedure of Standard Grounding in Power Transformer Substations

1. Specify $1.5 \times 1.5 \times 2.0 \mathrm{~m}$ earth pit, $150 \mathrm{~mm}^{2} \times 1$ copper earth conductor, $0.1 \times 2.4 \mathrm{~m}$ copper earth rod and Earth Grid of $1 \times$ b x $0.6 \mathrm{~m}$. Where, $\mathrm{l}$ and $\mathrm{b}$ are respectively length and breadth of the space occupied by the equipment to be protected.

2. Excavate earth grid and the desire number of earth pits. If unable to achieve wet soil after excavation depth of $2 \mathrm{~m}$, increase excavation depth till the desired results is achieved.

3. The Earthing Material i.e wood coal, Animal dung, water \& sand are poured into the earth pit in layers shown in figure 2. Wood coal used as good conductor of electricity while Sand is used to form porosity to cycle water and humidity around the mixture.

4. Put copper earth rod of size $0.1 \times 2.4 \mathrm{~m}$ in the mid of mixture.

5. Insert/bury 4No. Copper earth rod per pit as shown figure 3

6. Lay Copper Conductor round the Earth grid and terminate by soldering or mechanical joining at the two ends.
7. Use copper conductor to bond the two earth rods in each pit and connect the two ends to the grid via soldering.

8. Measure the resistance (R) of each of these pits conductor to $15 \mathrm{~m}$ around the earth pit with another conductor dip on earth at least $0.6 \mathrm{~m}$ deep. Each of these resistances should be maintained at a value less than one ohm.

9. Obtain the equivalent resistance $\left(R_{T 1}\right)$ for $R_{1}, R_{2}, R_{3}$, $R_{4}, R_{5}$ and $R_{6}$. The $R_{T 1}$ value should be closer to zero ohm as much as possible for an injection substation and less than $5 \Omega$ for the Distribution transformer substation.

10. Check voltage between earth pit conductor to neutral of mains supply 220 A.C, $50 \mathrm{~Hz}$. The result should be less than 2.0 Volts.

4.2 Procedure of Standard Grounding in Distribution Transformer Substations.

1. Specify $0.1 \times 1.8 \mathrm{~m}$ Earth rod, $70 \mathrm{~mm}^{2} \times 1$ copper earth conductor, $1.5 \times 1.5 \times 2$ m Earth pit dimension and Earth Grid of $1 \times \mathrm{b} \times 0.6 \mathrm{~m}$. Where, 1 and $b$ are respectively length and breadth of the space occupied by the equipment to be protected.

2. Excavate Earth Grid and the desire number of Earth Pits. If unable to achieve wet soil after excavation depth of $2 \mathrm{~m}$, increase excavation depth till the desired results is achieved.

3. The Earthing Material i.e wood coal, Animal dung, water \& sand are poured into the earth pit in layers shown in figure 4. Wood coal used as good conductor of electricity while Sand is used to form porosity to cycle water and humidity around the mixture.

4. Put Copper or Galvanize earth rod of size 0.1 $\mathrm{x} 1.8 \mathrm{~m}$ in the mid of mixture.

5. Insert/bury 2 No Earth rod per pit (copper or galvanized earth rod type) as shown in figure 5.

6. Lay Copper Conductor round the Earth grid and terminate by soldering at the two ends.

7. Use copper conductor to bond the two earth rods in each pit and connect the two ends to the grid via soldering.

8. Measure the resistance (R) of each of these pits conductor to $15 \mathrm{~m}$ around the earth pit with another conductor dip on earth at least $0.6 \mathrm{~m}$ deep. Each of these resistances should be maintained at a value less than one $\mathrm{Ohm}$.

9. Obtain the equivalent resistance $\left(R_{T 2}\right)$ for $R_{1}, R_{2}, R_{3}$ and $R_{4}$. The $R_{T 2}$ value should be less than $5 \Omega$ for the Distribution transformer substation. 
10. Check voltage between earth pit conductor to neutral of mains supply 220 A.C, 50 Hz. The result should be less than 2.0 Volts.

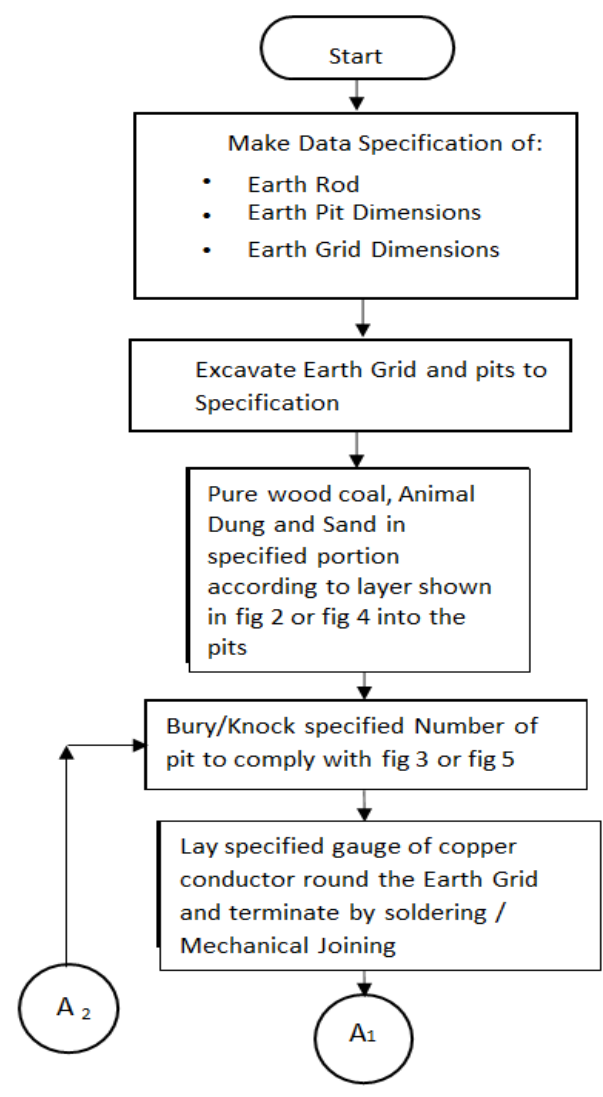

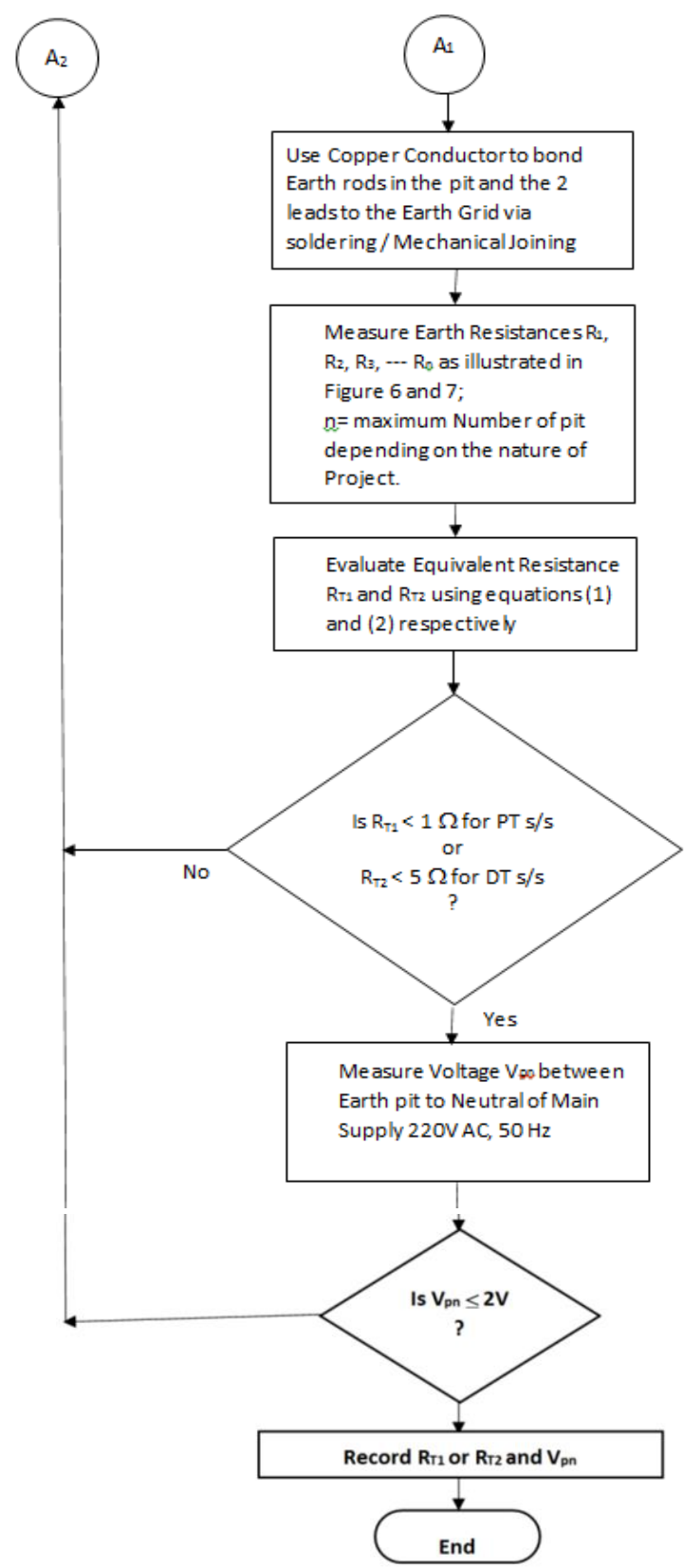

Figure 1: Flow Process of effective grounding of Transformers in both PT and DT Substations.

\section{DESCRIPTION OF CASE STUDY}

Oke Ira 2X15MVA, 33/11KV Injection Station that takes source from Ajah Transmission in Eko Electricity Distribution Company, Lagos State, Nigeria is used as a case study. At the completion of the project, the result of the conventional formal earthing system of the injection substation was obtained to be $3.5 \Omega$ due to the swampy nature of the land. The procedural steps described in subsection 4.1 and flow process of Figure 1 were applied to the installation shown in Figure 6.

In Figure 6, the earth wire called grid wire is laid without connected to any wire and soldered at the meeting point. Then, the Six earth pit is being dug
$1.5 \times 1.5 \times 2 \mathrm{~m}$ well treated and two earth rods is buried and well connected. The lead is then being brought out by clamp and each earth pit is connected to already laid grid wire in parallel. The resistance of the earth pit R1, $\mathrm{R} 2, \mathrm{R} 3, \mathrm{R} 4, \mathrm{R} 5$ and R6 were measured and recorded as shown in Table 1. Substituting the above resistance values in equation (1), the equivalent resistance is calculated as $\mathrm{R}_{\mathrm{T} 1}=0.47 \Omega$. Consequently, the newly developed earthing standard has really made it possible to get values of our earthing within the prescribed international value of $<1 \mathrm{Ohm}$.

Further application of the procedures in subsection 4.2 and the flow process in Figure 1 to 500 KVA 33/0.415 
$\mathrm{kV}$ Distribution Transformer Substation in the same location as above yielded a more improved Earthing results. The difference lies in the fact that in this case, 4 No Earth Pits instead of 6 No Earth pits used at power Transformer substation were required to be dug. The resistance of the Earth pit R1, R2, R3 and R4 were also measured and recorded as shown in Table 2 . Substituting these resistance values in equation (2), the equivalent resistance $\left(R_{T 2}\right)$ is obtained to be $0.54 \Omega$. The circuit arrangement of this Grounding of a typical 500 KVA, 33/0.415 kV Distribution Transformer substation is shown in Figure 7.

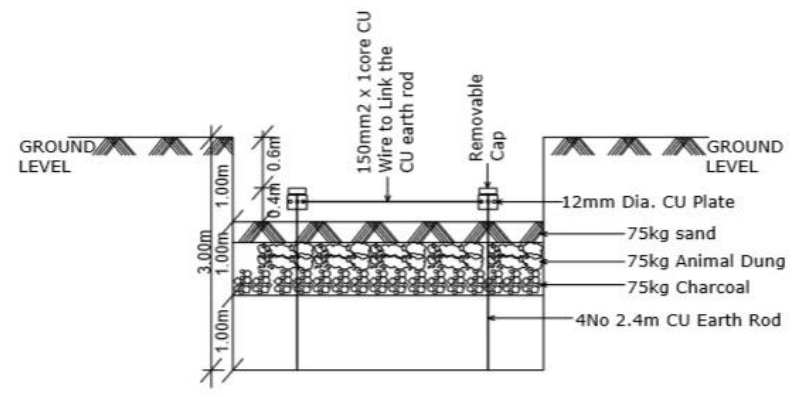

Figure 2: Cross Sectional View of Earth Pit Contents in PT Substation

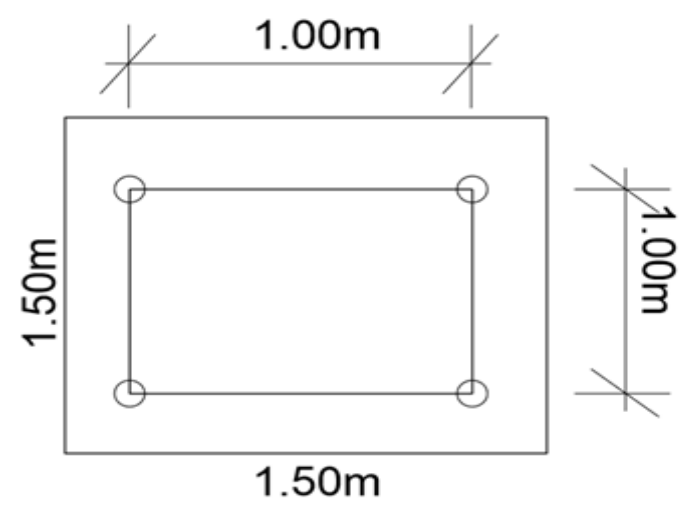

Figure 3: Plan View of Earth Rods in PT Substation Pit

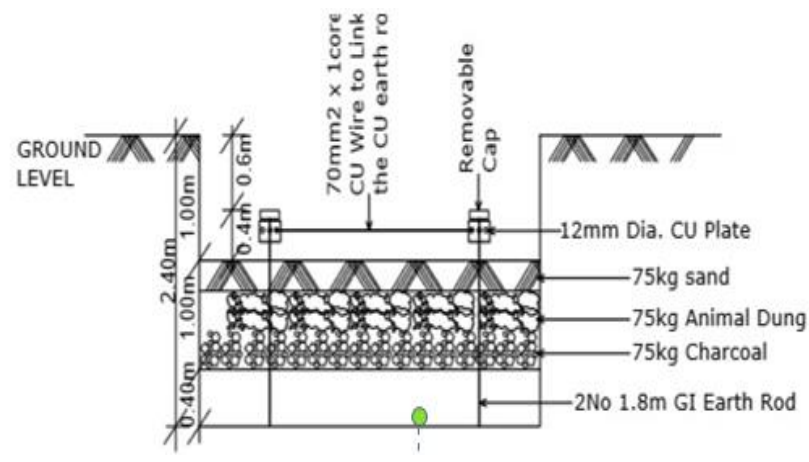

Figure 4: Cross Sectional View of Earth Pit Contents in DT Substation

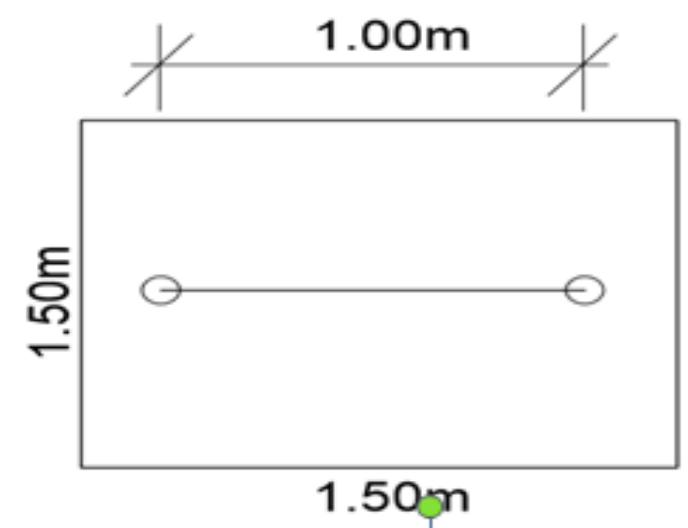

Figure 5: Plan View of Earth Rods in DT Substation Pit

Table 1: List of Symbols and their Descriptions

\begin{tabular}{ll}
\hline Symbol & Description \\
\hline 0 & Earth Pit
\end{tabular}

$150 \mathrm{~mm}^{2}$ x $1 \mathrm{Cu}$ Bonding Earth Rod and the Earth Grid for PT Station $70 \mathrm{~mm}^{2} \times 1 \mathrm{Cu}$ Bonding Earth Rod and the Earth Grid for DT Station
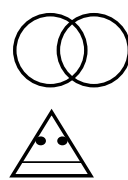

$\mathrm{N}$

CT

VT

LA

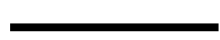

\begin{tabular}{ll} 
& (Earth Grid) \\
& Two connections made for each \\
S/S & Earth Pit to the Grid. \\
G/ISO & Substation \\
CB & Gang Isolator \\
Pro & Circuit Breaker \\
PT & Proposed \\
DT & Power Transformer \\
Cu & Distribution Transformer \\
\hline
\end{tabular}

Transformer

Ring Main Unit (RMU)

Transformer Neutral Connection with Earth Pit

Current Transformer

Voltage Transformer

Lightning Arrester

Earth Grid

Two connections made for each power equipment to the main Grid (Earth Grid).

Two connections made for each Copper Conductor 
Table 2: Measured Earth Pit Resistance in Case Study 1

\begin{tabular}{cc}
\hline Earth Pit & Measured Resistance (Ohms) \\
\hline 1 & 2.4 \\
2 & 2.8 \\
3 & 3.7 \\
4 & 2.9 \\
5 & 3.3 \\
6 & 2.2 \\
Equivalent Resistance, $\mathrm{R}_{\mathrm{T} 1}=0.47 \Omega$ \\
\hline
\end{tabular}

Table 3: Measured Earth Pit Resistance in Case Study 2

\begin{tabular}{cc}
\hline Earth Pit & Measured Resistance (Ohms) \\
\hline 1 & 1.5 \\
2 & 2 \\
3 & 2.5 \\
4 & 3.7 \\
Equivalent Resistance, $\mathrm{R}_{\mathrm{T} 2}=0.54 \Omega$
\end{tabular}

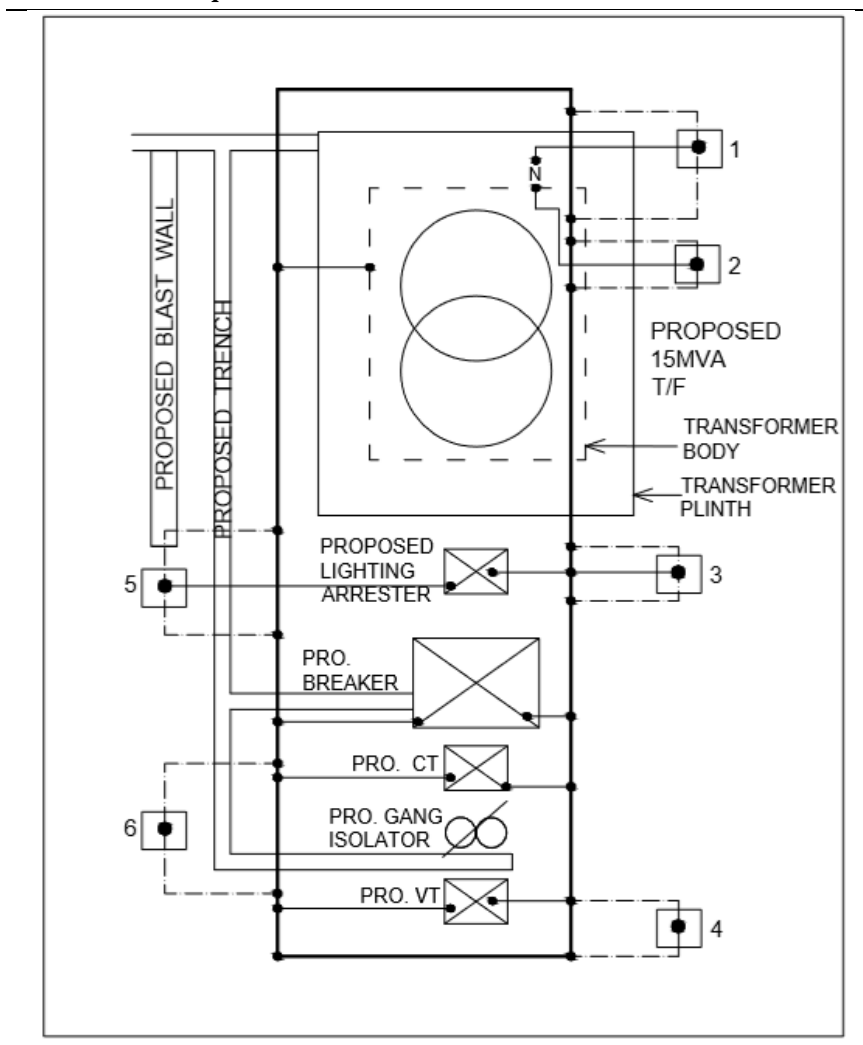

Figure 6: Line Diagram of a 15 MVA, 33/11kV Power Transformer Substation Earthing.

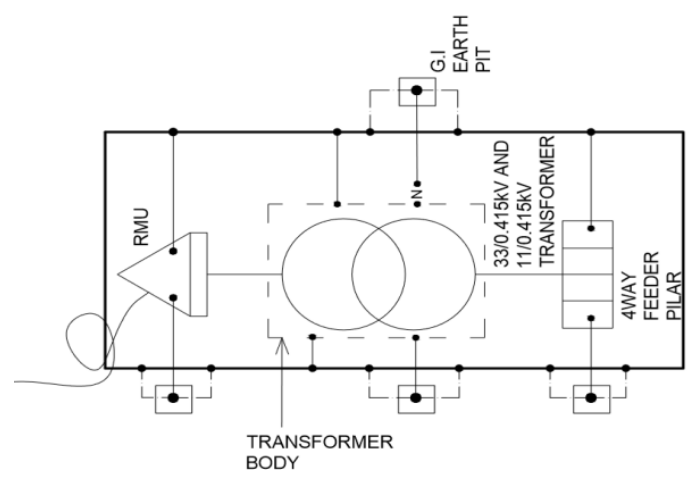

Figure 7: Line Diagram of a $500 \mathrm{kVA}, 33 / 0.415 \mathrm{kV}$ Distribution Transformer Substation Earthing.

\section{RESULTS AND DISCUSSION}

The pre-commissioning test results of the two case study projects are shown in Tables 2 and 3 . These results revealed that the equivalent Earth resistance, $\mathrm{R}_{T}$ of 15 MVA 33/11 kV Power Transformer substation and $500 \mathrm{KVA} 33 / 0.415 \mathrm{kV}$ Distribution Transformer substation are $0.47 \Omega$ and $0.54 \Omega$ respectively. However, it is required that for a PT substation, $\mathrm{R}_{\mathrm{T}}<$ $1 \Omega$ and DT Substation, $\mathrm{R}_{\mathrm{T}}<5 \Omega$ are generally the acceptable standards [4,5]. Indeed, the two $\mathrm{R}_{\mathrm{T}}$ Values follow the two inequality relations described above.

The challenges that are often encounter in carrying out the implementation of the substation grounding approach has been taken care of. These includes,

1. Ensuring Married Joint are cleverly carried out by Welding via Soldering/Mechanical joining rather than using binding wire. This prevent easy separation (losing of wires) which may results in high resistance.

2. Ensuring that Materials and equipment specifications are strictly complied with.

It is important to state that the use of Animal dung and wood coal is to fasten the attainment of results and minimizing cost. Otherwise, same results could be achieved by putting up more pits that will consume more materials such as Earth rods, Grid Conductor etc. From Figures $6 \& 7$, it can be seen that each earth pit contents and equipment are connected to the earth grid twice (Parallel connections).

From Engineers field experience, it has been observed that the conventional approach to power system equipment grounding is cumbersome because part of the process are several times repeated before the results are achieved. In the old way of doing earthing, a big earth pit is dug and several earth rods are driven in to the earth pit. Then the earth wire is connected across all the earth rods while 1 or 2 earth lead(s) is/are brought out. The earth lead is extended to other apparatus through married joint. At this point of connection, a resistance is developed which opposes the free flow of earth current. This makes the approach and the results obtained unreliable. For an illustration using Nigeria as an example, unpatriotic Nigerians vandalise the copper wire used as connecting lead for earthing of power equipment. This action is often unreported and unknown to power utility company. The vandalism is very common in Distribution Transformer substations and the affected substation will now be in operation unearthed since 1 or 2 leads brought out from the earth pit is Vandalised from the source. The overall consequence includes; possibility of 
shortening the lives of the equipment, thereby putting the utility customers in darkness and loss of revenue to utility company.

The new approach to equipment grounding has therefore eliminated the problems being faced in convectional approach. For example,

- The connection of each power equipment in the substation to Earth pit is dual from the earth grid.

- More than one Earth pits are used in each case study.

- The problem of repeated process before getting reliable result in the conventional method of earthing is eliminated. This is because the result in this method is obtained at once.

- Period required for the for the commissioning of the Transformer substation (i.e connection to Grid) is drastically reduced

- Effects of copper conductor vandalism is minimized.

- Loss of power utility equipment and revenue would be drastically reduced.

Thus, the reliability of this newly improved power equipment grounding method is high.

\section{CONCLUSION}

Grounding of power system equipment in substations is a phenomenon that engineers must attach great concern with. This became necessary to save the lives of the equipment as well as personnel handling the equipment. It enhances security of personnel and minimizes installation maintenance cost. The paper has presented the importance of Grounding of Power System equipment in substations. A flexible approach to this Earthing contrary to the old approach that involves creating Earth Mat without even achieving results in time is introduced. A flow process to achieve this new approach was developed and presented. The Developed flow process was applied to two case study; a $15 \mathrm{MVA}, 33 / 11 \mathrm{kV}$ PT substation and a $500 \mathrm{kV}$, $33 / 0.415 \mathrm{kV}$ DT substation. The results obtained in the two - case studied are presented and discussed. These results are satisfactory, reliable and obviously in compliance with IEEE Standards. Thus, the new approach is highly recommended to power utility companies.

\section{REFERENCES}

[1] Al. Nami A., Al. Qarni K., Al. Shahrani S. and Al. Juhani M.; "Design of Substation grounding grids",
Electrical Engineering Department, Faculty of Engineering, Jazan University, pp.1-64, 2014.

[2] Fink, G. D. and Beaty, W. H. Standard Handbook for Electrical Engineers, McGraw-Hill, USA, 2000.

[3] Beltz, R., Peacock, L. and William, V.P.E; "Application Considerations for high Resistance ground retrofits in pulp and paper Mills"; http://www.eaton.us/ecm/groups/public/@pub /@electrical/documents/pu02701001e.pdf" $2^{\text {nd }}$ February, 2018.

[4] Shah, S. G. and Bhasme, N. R. "Design of Earthing system for HV/EHV AC Substation", International Journal of Advance in Engineering \& Technology, Volume 6, Issue 6, pp.2597-2605, 2014.

[5] Adelian, M. A. "Improvement of Substation Earthing", International Journal of Engineering .and Advanced Technology, Volume 3, Issue 4, pp 100-104, April 2014.

[6] IEEE Standard 80 -: IEEE guide for safety in Alternating current in substation grounding, 2000.

[7] IEEE Standard 142-2007: Recommended Practice for Grounding of Industrial and commercial power systems. Chapter 4 page 164

[8] IEEE Standard 81: Guide for measuring Earth Resistivity, Ground Impedance and Earth Surface Potentials of a ground system.

[9] IEEE 1100 -: Powering and Grounding Electronics Equipment. 2005

[10] Bakkabulindi, G. "Planning Models for Single Wire Earth Return Power Distribution Networks", Licentiate Thesis, Royal Institute of Technology, Stockholm, Sweden, December, pp.9 - 71. 2012.

[11] Obeta, C. N. and Nnadi, D. B. N. "Performance Assessment of Substation Site Earthing using Fluke 1625 Ground Tester", Nigerian Journal of Technology, Vol. 32, No. 1, March, pp.49-53, $2013 .$.

[12] Oluseyi, P. O., Akinbulire, T. O. and Amahian, 0. "Investigation of the Lightning Arrester Operation in Electric Power Distribution Network", Nigerian Journal of Technology, Vol. 37, No. 2, April 2018, pp. 490 - 497.

[13] Engineer Educators (2007 - 2008); "Grounding and Bonding Electrical Systems", http://www.engineereducators.com/docs/groun dingandbonding2-2.pdf, pp.1-34, 2007 - 2008.

[14] Theraja, B. L. and Theraja, A. K. A Textbook of Electrical Technology, S. Chand Company Ltd, Hardback, India, 2005 